\title{
The Growth and Plankton Changes of Intensive Ecological Aquaculture Model of Pseudosciaena crocea
}

\author{
Ruan Chengxu and Yuan Chonggui*
}

College of Biological Science and Technology, Fuzhou University, Fuzhou, Fujian 350116, China

\begin{abstract}
The growth of Pseudosciaena crocea and changes of plankton were studied under intensive ecological aquaculture model that does not involve any change in water. The results indicated that: the growth rate of Pseudosciaena crocea was significantly higher than that in cage culture $(\mathrm{p}<0.05)$, the essential amino acids, flavor amino acids and total amino acids of Pseudosciaena crocea were significantly higher than that in cage culture $(\mathrm{p}<0.05)$, the PUFA and DHA、EPA of Pseudosciaena crocea were also significantly higher than that in cage culture $(\mathrm{p}<0.05)$. Plankton biomass of aquaculture water increased with the cultivation time. The diversity of phytoplankton was better in the early stage, the diversity index and evenness index decreased in the later stage, and the diversity of phytoplankton was poor at the end of the experiment. The diversity of zooplankton was better along with a slightchange in its diversity index and evenness index with the zooplankton being in an equilibrium state.
\end{abstract}

Keywords: Ecological aquaculture, Growth, Plankton, Pseudosciaena crocea.

\section{INTRODUCTION}

Pseudosciaena crocea (Richardson) is a member of Perciformes, belonging to Sciaenidae and Pseudosciaena, commonly known as cucumber fish or yellow croaker [1]. It is one of the four main economic fishes and can be found in the list [2]. Recently, its culture model is represented as the cage culture model in seawater, which depends more on the natural weather condition and has a long growth cycle, easy to be affected by such natural disasters as typhoon and red tides and also from the pollution in seawater. All the problems mentioned above can not be ignored, as these cause difficulties for the culture of Pseudosciaena crocea. By constructing simple production facilities and regulating various ecological factors, this study proposes an indoor intensive culture for Pseudosciaena crocea. Different from the high-investment and high-cost industrial recirculating aquaculture, the intensive culture mode is used to intensively culture the yellow croaker without changing water and utilizes the complete biological structure to realize the purification of water and the prevention from diseases.

\section{MATERIALS AND METHODS}

\subsection{Experimental Material}

The Experimental fishes were bought from Kengyuan Seedling Culture Site in Ningde, Fujian, belonging to Dong

*Address correspondence to this author at the College of Biological Science and Technology, Fuzhou University, Fuzhou, Fujian 350116, China; E-mail: fdycg@126.com
Nationality's Pseudosciaena crocea that grew in Guanjingyang around the area of Fujian and Guangdong. They were spring seedlings having body length of $1 \mathrm{~cm}$.

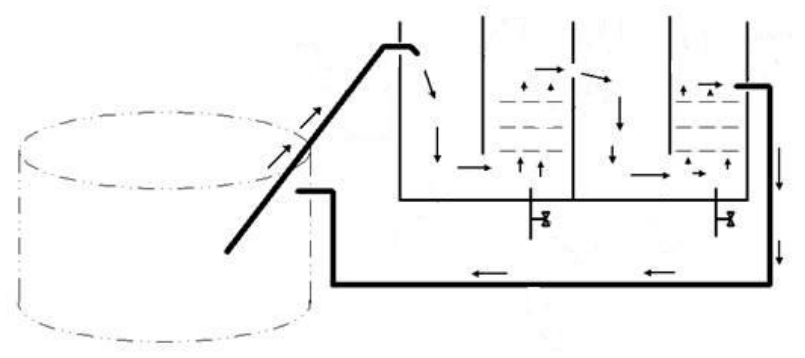

Fig. (1). Organic substance separation device of the breeding pool.

\subsection{Experimental Design}

The experiment was carried out in a plastic pool having a diameter of $4 \mathrm{~m}$ with $80 \mathrm{~cm}$ depth of water. A parallel group, in each pool with about 2300 tails of fishes was set up with a density of $228.9 \mathrm{tail} / \mathrm{m}^{3}$. The experimental seawater was the natural seawater with salinity of 25 , while some fresh water was added every 10 days and after 2 months, the salinity decreased to 15 . The pool was equipped with a microtubule aeration device that could aerate and provide oxygen for 24 hours to ensure the dissolved oxygen> $5.0 \mathrm{mg} / \mathrm{L}$, a water plumbing and heating device to ensure the temperature of water $\geq 25^{\circ} \mathrm{C}$ and a self-designed organic substance separation device to separate the organic substance (see Fig. 1). In the device as shown in Fig. (1), the gas pipe was set up at the bottom of the pool and with the 
Table 1. Evaluation standard for the biodiversity threshold.

\begin{tabular}{|c|c|c|}
\hline Evaluation & Threshold & Level Description \\
\hline \hline I & $<0.6$ & Poor \\
\hline II & $0.6-1.5$ & Commonly \\
\hline III & $1.6-2.5$ & Better \\
\hline IV & $2.6-3.5$ & Rich \\
\hline V & $>3.5$ & Very Rich \\
\hline
\end{tabular}

help of gas, the waste was absorbed in the precipitation tank, the inlet of which was higher than overflow hole and with the help of separation board, the water flowed into another precipitation tank along with the overflow hole and finally the water was sent back to the pool by the returned tube that was connected with this precipitation tank to complete the purification of water. Meanwhile, the precipitated waste could also be discharged out of the tank by the blow-down valve.

\subsection{Culture Management}

In the childhood phase, depending on their size, the fishes are fed with Hippo-brand slowly sinking feed with a combination of copepods and cladocerans for several times. When growing into the juvenile phase, they are fed Hippobrand slowly sinking feed and at intervals are put into appropriate cladocerans for 4 times each day. When the body length of fishes grows to about $10 \mathrm{~cm}$, they are fully fed Xialin-brand extruded feed for 3 times a day and after they are finished, the rest of the feed is removed. During the whole phase of culture, in order to keep the dynamic equilibrium, the water should not be changed but the $\mathrm{pH}$ value was adjusted by lime to keep it in 7-8.

\subsection{Experimental Project and Methods}

After finishing the experiment, 20 tails were randomly selected from every pond to carry out statistical data of the growth pattern.

15 tails of Pseudosciaena crocea were randomly selected to study the quality of meat. After the experiment was finished, the Dong nationality of Pseudosciaena crocea in Fujian and Guangdong cultured by cage was bought in Guanjingyang of Ningde as a comparison. To determine the meat quality, the fish scales were first scraped, then the meat was removed from the spine and the fish bone was removed from the meat, finally the meat was kept into the blender to cut it into paste, which was stored in the refrigerator at $4^{\circ} \mathrm{C}$ for determination. The methods used in the experiment included the Kjeldahl method to determine the content of crude protein, the Soxhlet method to determine the content of crude fat, the Hitachi 835-50 type amino acid autoanalyzer to determine amino acids and the Shimadzu GC2010 gas chromatograph to determine the fatty acids after the effect of methyl esterification from benzene-petroleum ether lipids.

The samples of plankton were selected every 30 days for the study. The method utilized for selecting phytoplankton sampleinvolved relative selection of $500 \mathrm{ml}$ water sample from the middle level of water in the middle of or around the experimental pool and after mixing that together, $500 \mathrm{ml}$ was selected to be fixed by $1.5 \%$ lugol. The method incorporated for the selection of zooplankton sample included selection of $1 \mathrm{~L}$ water sample which was fixed by $5 \%$ formalin. In the laboratory, optical microscope was used to identify the species and to analyze the data.

Evaluation standard for the biodiversity threshold can be seen in Table $\mathbf{1}$ [3].

The content of $\mathrm{NH}_{4}^{+}-\mathrm{N}$ can be determined by the Nessler's reagent colorimetric method [4] and the content of $\mathrm{NO}_{2}{ }^{-}-\mathrm{N}$ can be determined by Naphthylethylenediamine spectrophotometry (GB17378.4-1998, 1999).

\subsection{Data Statistics}

The diversity index of plankton is calculated by Shannon-Weaver index equation [5].

The diversity index $H^{\prime}=-\sum_{i=1}^{s} P i \log _{2} P i ; P i=\mathrm{ni} / N$

Where $\mathrm{S}$ represents the total number of species in sample, $\mathrm{Pi}$ is ni/ $\mathrm{N}$ (ni the number of the $\mathrm{i}$ species, $\mathrm{N}$ the total number).

The evenness index of plankton is calculated by Pielou index equation [6].

The evenness index $J=H^{\prime} / \log _{2} \mathrm{~S}$.

$\mathrm{S}$ represents the total number of species in sample.

SPSS17.0 can be applied to the growth data of Pseudosciaena crocea to carry outsingle factor variance analysis. If the difference is significant $(\mathrm{P}<0.05)$, then the Duncan's multiple comparison can be utilized for further analysis.

\section{RESULT AND ANALYSIS}

\subsection{The Growth Performance of Pseudosciaena crocea}

The experiment was carried out from March 5 to August 28 , stretching on to a total of 176 days and in this process, it did not break out any disease without any use of drugs and water change as described in Table 2 . According to the survey, the growth performance of the same batch of spring seedling cultured in the cage of Sanduao, Ningde was as 
Table 2. The growth performance of juvenile Pseudosciaena crocea.

\begin{tabular}{|c|c|c|c|c|c|c|}
\hline Date (m.d) & Body Quality (g) & Body Length (cm) & Fatness (\%) & $\begin{array}{l}\text { Breeding Density } \\
\left(\text { Tail } / \mathbf{m}^{3}\right)\end{array}$ & Feed Efficiency $(\%)$ & Survival Rate(\%) \\
\hline 3.05 & $0.03 \pm 0.00$ & $1.47 \pm 0.09$ & - & $228.90 \pm 0.00$ & - & $100.00 \pm 0.00$ \\
\hline 8.28 & $53.49 \pm 2.71$ & $14.98 \pm 0.51$ & $1.60 \pm 0.11$ & $101.37 \pm 9.92$ & $88.74 \pm 2.16$ & $44.28 \pm 4.33$ \\
\hline
\end{tabular}

Table 3. Effects of ecological culture and cage culture on conventional nutrients of juvenile Pseudosciaena crocea (\%).

\begin{tabular}{|c|c|c|c|c|}
\hline Stem From & Water Content & Crude Protein & Crude Fat & Crude Ash \\
\hline \hline Ecological culture & $73.78 \pm 0.38 \mathrm{a}$ & $17.55 \pm 0.42 \mathrm{a}$ & $7.36 \pm 0.29 \mathrm{a}$ & $1.09 \pm 0.06 \mathrm{a}$ \\
\hline Cage culture & $75.21 \pm 0.43 \mathrm{~b}$ & $16.61 \pm 0.28 \mathrm{~b}$ & $6.88 \pm 0.17 \mathrm{a}$ & $1.21 \pm 0.15 \mathrm{a}$ \\
\hline
\end{tabular}

follows: body quality: $36.58 \pm 3.27 \mathrm{~g}$, body length: $14.21 \pm 0.58 \mathrm{~cm}$ and the fatness : $1.28 \pm 0.11 \%$, which shows that its growth speed was significantly lower than the speed of those experimental fishes $(p<0.05)$. Compared with some cage experimental results from other scholars $[7,8]$, the speed was faster and the feed efficiency was higher in this experiment (Tables 3-5).

\subsection{The Change of Plankton's Structure in Cultured Waters}

As can be seen in Tables 6 and 7, in the early stage of experiment, the biomass of phytoplankton was small, as it did not succeed to establish the stable ecological structure. When developing into the middle and later stage, its biomass increased, mainly concentrating on pyrrophyta, bacillariophyta and chlorophyta. Especially in August, it mainly increased in pyrrophyta, which was due to the succession of water in this experiment. During this stage, owing to the culture implementation indoors and lack of enough light, the chlorophyta had no growth advantage and with the increase in feed, the $\mathrm{NH}^{4+}-\mathrm{N}$ concentration rose, which proved beneficial for the growth of pyrrophyta.

The change in tendency of zooplankton was as follows: with the extension of culture time, the biomass of copepods increased and the rotifer decreased while the protozoan kept an inverse tendency for the rotifer. In the early stage of the experiment, the seedlings of zooplankton were fed with copepods, so the data at this time was not interfered. At this stage, the seedlings ate copepods, which resulted in no change in the biomass of copepods but in rotifer. The biomass of rotifer increased to a large number until May, which restricted the increase in protozoan. But Pseudosciaena crocea during its growth did not eat any more copeods in the middle and the latter of experiment, which then resulted in an increase in copepods and decrease in rotifer.

From Table 8, it has been observed that the diversity of phytoplankton performs well in the early stage, for it cultures in natural seawater with complicated phytoplankton. Developing into the later stage, owing to the lack of light and the effect of high $\mathrm{NH}^{4+}-\mathrm{N}$, the diversity performs badly with the decrease in diversity index and evenness index while the diversity of zooplankton is good, mainly because its culture system is a closure system without any invasion of alien species with the environmental ecological factors being stable.

\subsection{The Change of Water Quality in Cultured Waters}

From Fig. (2), it is found that in the first three months, the concentrations of $\mathrm{NH}^{4+}-\mathrm{N}$ and $\mathrm{NO}_{2}{ }^{-}-\mathrm{N}$ increased slowly, for they had less feed and produced little pollution having a small body at this stage. After three months, with the increase in eating and pollution, the concentrations rose rapidly. Since in this experiment, the culture model without changing water was applied, therefore the pollution was severe. However, in the later stage, the increased speed slowed down and the concentrations of $\mathrm{NH}^{4+}-\mathrm{N}$ and $\mathrm{NO}_{2}{ }^{-}-\mathrm{N}$ were under control, as the succession of water is suitable for the water environment with high $\mathrm{NH}^{4+}-\mathrm{N}$.

\section{DISCUSSION}

In this experiment, the method of intensive ecological model without changing water was applied to culture Pseudosciaena crocea resulting in a technical effect of culturing Pseudosciaena crocea at high density. Different from the crude ecological culture model, this experiment model is a high-density intensive culture and is different from the popular greenhouse intensive model in which $100 \%$ water needs to be changed, while the model in this experiment did not involve any change of water or drug usage. Meanwhile, by establishing the ecological equilibrium in water, it used dynamic equilibrium between microorganisms and cultured fishes to discompose the metabolic waste and let the water have the ability to purify itself and resist diseases, which in turn saved water and settled the problem of drug's residue from the source.

As a kind of poikilotherm, fishes' metabolic rate is determined by temperature $[9,10]$. In this study, it implemented the culture by controlling and maintaining the temperature 
Table 4. Effects of ecological culture and cage culture on amino acid compositions of muscle of juvenile Pseudosciaena crocea (\% DW).

\begin{tabular}{|c|c|c|}
\hline Amino Acid & Ecological Culture & Cage Culture \\
\hline Lysine & $5.45 \pm 0.09^{\mathrm{a}}$ & $5.39 \pm 0.04^{\mathrm{a}}$ \\
\hline Threonine & $2.65 \pm 0.03^{\mathrm{a}}$ & $2.62 \pm 0.05^{\mathrm{a}}$ \\
\hline Serine & $2.15 \pm 0.04^{\mathrm{a}}$ & $2.30 \pm 0.08^{\mathrm{b}}$ \\
\hline Glutamate & $10.41 \pm 0.45^{\mathrm{a}}$ & $9.92 \pm 0.31^{\mathrm{a}}$ \\
\hline Glycine & $2.95 \pm 0.04^{\mathrm{a}}$ & $3.17 \pm 0.10^{\mathrm{b}}$ \\
\hline Alanine & $3.47 \pm 0.04^{\mathrm{a}}$ & $3.32 \pm 0.04^{\mathrm{b}}$ \\
\hline Cystine & $0.36 \pm 0.03^{\mathrm{a}}$ & $0.57 \pm 0.02^{\mathrm{b}}$ \\
\hline Valine & $2.84 \pm 0.05^{\mathrm{a}}$ & $2.76 \pm 0.04^{\mathrm{a}}$ \\
\hline Methionine & $1.89 \pm 0.04^{\mathrm{a}}$ & $1.65 \pm 0.03^{\mathrm{b}}$ \\
\hline Isoleucine & $3.75 \pm 0.03^{\mathrm{a}}$ & $3.18 \pm 0.03^{\mathrm{b}}$ \\
\hline Leucine & $4.98 \pm 0.06^{\mathrm{a}}$ & $4.68 \pm 0.09^{b}$ \\
\hline Tyrosine & $2.75 \pm 0.06^{\mathrm{a}}$ & $1.77 \pm 0.03^{\mathrm{b}}$ \\
\hline Phenylalanine & $2.41 \pm 0.04^{\mathrm{a}}$ & $2.45 \pm 0.03^{\mathrm{a}}$ \\
\hline Aspartic Acid & $6.58 \pm 0.05^{\mathrm{a}}$ & $5.58 \pm 0.09^{\mathrm{b}}$ \\
\hline Histidine & $1.22 \pm 0.05^{\mathrm{a}}$ & $0.91 \pm 0.02^{\mathrm{b}}$ \\
\hline Arginine & $3.45 \pm 0.07^{\mathrm{a}}$ & $3.33 \pm 0.05^{\mathrm{a}}$ \\
\hline Proline & $1.87 \pm 0.05^{\mathrm{a}}$ & $1.16 \pm 0.05^{\mathrm{b}}$ \\
\hline Essential Amino Acid & $23.99 \pm 0.06^{\mathrm{a}}$ & $22.75 \pm 0.02^{\mathrm{b}}$ \\
\hline Flavor Amino Acid & $26.86 \pm 0.31^{\mathrm{a}}$ & $25.32 \pm 0.22^{\mathrm{b}}$ \\
\hline Total Amino Acids & $59.21 \pm 0.35^{\mathrm{a}}$ & $54.78 \pm 0.28^{\mathrm{b}}$ \\
\hline
\end{tabular}

Note: Values in the same row with different superscript letters are significantly $\operatorname{different}(P<0.05)$

Table 5. Effects of ecological culture and cage culture on fatty acid compositions of muscle of juvenile Pseudosciaena crocea (\%(DW).

\begin{tabular}{|c|c|c|}
\hline Fatty Acid & Ecological Culture & Cage Culture \\
\hline \hline Myristic Acid (C14:0) & $3.16 \pm 0.05^{\mathrm{a}}$ & $27.86 \pm 0.08^{\mathrm{b}}$ \\
\hline Palmitic Acid (C16:0) & $27.31 \pm 0.46^{\mathrm{a}} \pm 0.25^{\mathrm{a}}$ & $11.17 \pm 0.11^{\mathrm{a}}$ \\
\hline Palmitic Acid (C16:1) & $11.18 \pm 0.09^{\mathrm{a}}$ & $5.21 \pm 0.18^{\mathrm{b}}$ \\
\hline Stearic Acid (C18:0) & $4.15 \pm 0.07^{\mathrm{a}}$ & $23.58 \pm 0.17^{\mathrm{b}}$ \\
\hline Oleic Acid (C18:1) & $21.65 \pm 0.05^{\mathrm{a}}$ & $1.19 \pm 0.04^{\mathrm{a}}$ \\
\hline Linoleic Acid (C18:2) & $1.15 \pm 0.02^{\mathrm{a}}$ & \\
\hline
\end{tabular}


Table 5. contd..

\begin{tabular}{|c|c|c|}
\hline Fatty Acid & Ecological Culture & $0.52 \pm 0.02^{\mathrm{a}}$ \\
\hline \hline Linolenic Acid (C18:3) & $0.54 \pm 0.03^{\mathrm{a}}$ & $0.55 \pm 0.02^{\mathrm{b}}$ \\
\hline Parinaric Acid (C18:4) & $0.63 \pm 0.02^{\mathrm{a}}$ & $0.46 \pm 0.02^{\mathrm{b}}$ \\
\hline Arachidonic Acid (C20:0) & $0.62 \pm 0.01^{\mathrm{a}}$ & $1.93 \pm 0.05^{\mathrm{b}}$ \\
\hline Arachidonic Acid (C20:1) & $0.96 \pm 0.03^{\mathrm{a}}$ & $4.22 \pm 0.08^{\mathrm{b}}$ \\
\hline EPA (C20:5) & $5.30 \pm 0.10^{\mathrm{a}}$ & $1.13 \pm 0.02^{\mathrm{a}}$ \\
\hline Erucic Acid (C22:1) & $1.19 \pm 0.06^{\mathrm{a}}$ & $14.18 \pm 0.06^{\mathrm{a}}$ \\
\hline DHA (C22:6) & $17.07 \pm 0.10^{\mathrm{a}}$ & $4.81 \pm 0.56^{\mathrm{a}}$ \\
\hline Others & $5.09 \pm 0.76^{\mathrm{a}}$ & $58.47 \pm 0.19^{\mathrm{a}}$ \\
\hline UFA & $58.59 \pm 0.23^{\mathrm{a}}$ & $20.66 \pm 0.17^{\mathrm{b}}$ \\
\hline PUFA & $24.69 \pm 0.12^{\mathrm{a}}$ & $18.40 \pm 0.10^{\mathrm{b}}$ \\
\hline DHA+EPA & $22.37 \pm 0.12^{\mathrm{a}}$ & \\
\hline
\end{tabular}

Note: Values in the same row with different superscript letters are significantly different $(\mathrm{P}<0.05)$

Table 6. Biomass of phytoplankton (104ind $\cdot L-1)$.

\begin{tabular}{|c|c|c|c|c|c|}
\hline Date & Cyanophyta & Pyrrophyta & Bacillariophyta & Chlorophyta & 0.42 \\
\hline \hline March 15 & 0.21 & 0.33 & 0.54 & 0.45 & 0.15 \\
\hline April 15 & 0.12 & 0.58 & 0.78 & 1.59 & 0.00 \\
\hline May 15 & 0.00 & 3.66 & 2.42 & 3.87 & 0.19 \\
\hline June 15 & 0.12 & 8.61 & 4.76 & 4.03 & 0.00 \\
\hline July 15 & 0.15 & 11.07 & 0.72 & 3.24 \\
\hline August 15 & 0.00 & 40.86 & & 0.06 \\
\hline
\end{tabular}

Table 7. Biomass of zooplankton (ind $\cdot L-1)$.

\begin{tabular}{|c|c|c|c|c|c|}
\hline March 15 & 180 & 75 & 60 & 900 & 240 \\
\hline May 15 & 195 & 225 & 495 & 450 & 203 \\
\hline July 15 & 435 & 165 & 0 & 750 & 338 \\
\hline August 15 & 375 & 105 & 45 & 450 & 188 \\
\hline
\end{tabular}


Table 8. Species diversity index and evenness index of plankton.

\begin{tabular}{|c|c|c|c|c|}
\hline \multirow{2}{*}{ Date } & \multicolumn{2}{|c|}{ Phytoplankton } & \multicolumn{2}{c|}{ Zooplankton } \\
\cline { 2 - 5 } & Diversity Index & Evenness Index & Diversity Index & Evenness Index \\
\hline \hline March 15 & 2.19 & 0.94 & 1.64 & 0.71 \\
\hline April 15 & 1.79 & 0.77 & 2.01 & 0.87 \\
\hline May 15 & 1.63 & 0.70 & 1.90 & 0.95 \\
\hline June 15 & 1.68 & 0.72 & 1.86 & 0.82 \\
\hline July 15 & 1.32 & 0.57 & 2.07 & 0.89 \\
\hline August 15 & 0.51 & 0.22 & & 0.80 \\
\hline
\end{tabular}

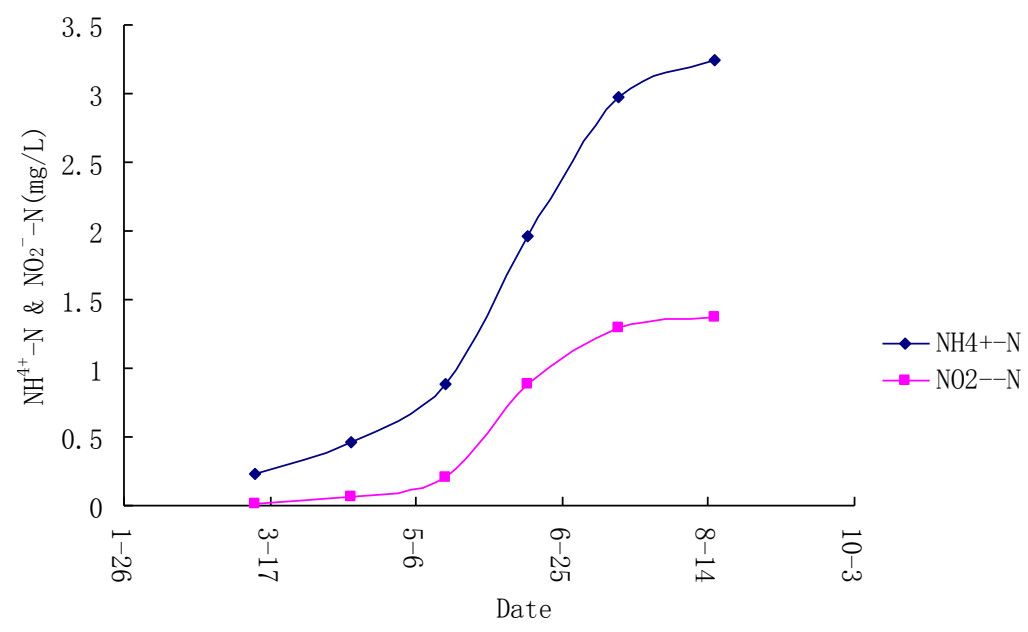

Fig. (2). The concentrations of $\mathrm{NH}^{4+}-\mathrm{N}$ and $\mathrm{NO}_{2}-\mathrm{N}$.

above $25^{\circ} \mathrm{C}$,making the growth rate higher than that cultured in cage. In general, the feeding rate, growth rate and feed efficiency rise along with the increase in temperature [11], which in turn influences the growth of fishes by impacting their feeding and feed utilization rate. The author proves that in his early study, the feeding amount, quality increase rate and specific growth rate rose and had significant differences along with the rise of temperature [12]. Therefore, the high growth rate and feed efficiency produced by the controlled temperature in the ecological culture can not be obtained in cage culture.

The composition of amino acids of meat is a key indicator for evaluating the nutritional value and flavor. Glutamate, aspartic acid, arginine, glycine and alanine are called flavor amino acids, the contents of which determine the flavor of the meat. In this study, essential amino acids and flavor amino acids of the muscles in intensive ecological culture are all higher than that in cage culture $(\mathrm{P}<0.05)$, illustrating that in intensive culture model, the Pseudosciaena crocea cultured by appropriate mixed feed has higher nutritional value and flavor, for the artificial mixed feed it uses more lipid contents. As from Campos's study, it is known that the content of amino acids in fish meat will rises along with the increase in lipids of the feed.

The composition of meat's fatty acid can be affected by the environment, feed and other external factors [13, 14]. Some studies have proved that the composition of fatty acids can reflect the fat contents of feed [15]. In this study, PUFA, DHA and EPA of Pseudosciaena crocea were all higher than that in cage culture model $(\mathrm{P}<0.05)$, mainly determined by the fats in artificial feed. DHA and EPA are beneficial for people's nutrition and health and can reduce the risk of suffering from coronary heart disease, asthma and inhibit the growth of tumor $[16,17]$, which shows that in intensive ecological model, the nutritional value cultured by appropriate feed is higher than that in conventional cage culture.

The plankton structure established in the intensive ecological model succeeds with the succession of culture process under stable condition in greenhouse and its variation also reflects the ecological characteristic of this model. In the early stage, the biomass of phytoplankton is small, reflecting 
good diversity while in the later stage, the biomass decreases, showing poor diversity, is similar to the variation of phytoplankton in the model of seawater culture [18]. The increase of phytoplankton is mainly due to the mixed water affected by fishes' activities and which propels the cycling of nutritional matters while the high-density culture promotes the increase of nutritional matters, especially the increase of $\mathrm{N}$ and $\mathrm{P}$ [19]. In other culture models in seawater, if there are filter feeding organisms, the biomass and diversity of phytoplankton are lowered [20]. In this study, however, culturing of Pseudosciaena crocea, does not belong to filter feeding organism, so the decrease in phytoplankton's diversity in later stage results from the environment. Considering the water quality, the rapid increase in the contents of $\mathrm{NH}^{4+}-\mathrm{N}$ propels the cultivation of pyrrophyta, which may result in the lowering of diversity. But in the later stage, the water load turns terrible owing to the poor diversity and high contents of $\mathrm{NH}^{4+}-\mathrm{N}$, so the change of water or other measures is required to improve the environment for carrying out further culture.

The feeding of fishes to zooplankton makes the zooplankton structure more simpler and lowers its diversity. In the early stage of this experiment, Pseudosciaena crocea consumed such large zooplankton as copepods. Therefore, the copecods were restricted in the early stage but increased rapidly in the later stage. The biomass of phytoplankton was closely related to that of zooplankton, which increased along with the growth of phytoplankton in the middle and the later stage, but the relationship of catching and getting caught among zooplanktons made copepods, rotifers and protozoa grow reciprocally. In the later stage, the diversity of zooplanktons was not affected since no such planktons consumed them.

Contrary to the change regulation of plankton in this study, the structure of plankton cultured in the open sea is influenced by the water temperature. However, the biomass and diversity of plankton are not impacted by the water temperature owing to the fact that it applies the temperature control culture model.

After analyzing the growth effect of Pseudosciaena crocea and the evolution of biological structure in waters, it was found that the model uses the high-density culture without changing water. It develops the natural evolution to a stable dynamic equilibrium,suitable for this ecological environment by controlling the ecological condition, enabling the growth of Pseudosciaena crocea in an appropriate environment. Thus the growth rate, feed efficiency, amino acids and fatty acids in this model are obviously higher than that in cage culture. During the whole experimental process, it did not suffer from large-scale plant diseases and insect pests and did not make use of any drugs. Though, in the later stage, the phytoplankton had poor diversity owing to the simple environmental factor and the high $\mathrm{NH}^{4+}-\mathrm{N}$ of water. The diversity and evenness indexes of zooplankton performed well, which shows that the phytoplankton and zooplankton remained in an equilibrium state, giving a complete and stable structure of plankton. Therefore, the intensive ecological model can be used to establish stable water biological structure, by realizing the factory culture of Pseudosciaena crocea and by applying the technical indicators of water saving, energy saving and environment protecting, overall providing a new path to this model of culture.

\section{CONFLICT OF INTEREST}

The authors confirm that this article content has no conflicts of interest.

\section{ACKNOWLEDGEMENTS}

This work is supported by The Scientific and Technological Project in Fuzhou University (0080822733).

\section{REFERENCES}

[1] Yuanding Z, Hanlin W. Records of Fujian Fishes(II) Fuzhou: Fujian Science and Technology Press, 1985.

[2] Cailan Z, Jiafu L, Yacui L. Analyzing the present condition and counter measure of cultured large yellow croaker Pseudosciaena crocea in fujian province. J Shanghai Ocean Univ 2002; 11: 77-83.

[3] Qingchao C, Liangmin H, Jianqiang Y. Study on the diversity of zooplankton in waters around nansha islands. Beijing: Ocean Press 1994.

[4] Jingping Z. Quickly determination of the ammonia-nitrogen in the seawater aquiculture by Nessler's reagent colorimetric method. Fujian Anal Test 2011; 20: 10-4.

[5] Shannon CE, Weaver W. The mathematical theory of communication. Urbana IL: University of Illinois Press, Chicago, IL., 1998; pp. 144.

[6] Pielou EC. An introduction to mathematical ecology, WileyInterscience, New York, 1969; pp. 294.

[7] Chen H, Guowen L, Zhankun L. Study on the growth characteristic of Pseudosciaena crocea in cage culture. Mar Sci 2010; 34: 1-5.

[8] Chengjin C. Observation on growth properties of cultured large yellow croaker, Pseudosciaena crocea. Modern Fish Inform 2011; 26: 24-9.

[9] Xiaojun X, Ruyong S. Study on the main ecological factor that influencing the metabolizing of fishes. J Southwestern Normal University (Natural Science Edition) 1989; 14: 141-9.

[10] Brett JR. Environmental factors and growth. New York: Academic Press 1979.

[11] Shimeno S, Shikata T. Effects of acclimation temperature and feeding rate on carbohydrate-metabolizing enzyme activity and lipid content of common carp. Nippon Suisan Gakkaishi 1993; 59: 661-6.

[12] Chengxu R, Defeng WU, Chonggui Y. Effects of temperature on the growth and hydrochemical state of juvenile Pseudosciaena crocea. J Guangzhou Univ 2013; 12: 36-9.

[13] Campos P, Martino RC, Trugo LC. Amino acid composition of brazilian surubim fish (Pseudoplatystoma coruscans) fed diets with different levels and sources of fat. Food Chem 2006; 96: 126-30.

[14] Bandarra NM, Batista I, Nunes ML, Christie WW. Seasonal changes in lipid composition of sardine (Sardine pilchardus). Food Sci 1997; 62: 40-2.

[15] Kiessling A, Pickova J, Johansson L, et al. Changes in fatty acid composition in muscle and adipose tissue of farmed Rainbow trout (Oncorhynchus mykiss) in relation to ration and age. Food Chem 2001; 73: 271-84.

[16] Chen IC, Chapman FA, Wei CI, Portier KM, O'Keefe SF. Differentiation of cultured and wild sturgeon (Acipenser oxyrinchus Desotoi) based on fatty acid composition. Food Sci 1995; 60: 631-5. 
[17] Justi KC, Hayashi C, Visentainer JV, Souza NE, Matsushita M. The influence of feed supply time on the fatty acid profile of Nile tilapia (oreochromis). Food Chem 2003; 80: 489-93.

[18] Conner WE. Importance of $n-3$ fatty acids in health and disease. Nutr 2000; 17: 171-5.
[19] Simopoulos AP. Omega-3 fatty acids in inflammation and autoimmune diseases. Nutr 2002; 21: 495-505.

[20] Pardini RS. Nutritional intervention with omega-3 fatty acids enhances tumor response to anti-neoplastic agents. Chem Biol Interact 2006; 162: 89-105.

Received: March 14, 2015

Revised: May 05, 2015

Accepted: May 09, 2015

(C) Chengxu and Chonggui; Licensee Bentham Open

This is an open access article licensed under the terms of the Creative Commons Attribution Non-Commercial License (http://creativecommons.org/licenses/ by-nc/4.0/) which permits unrestricted, non-commercial use, distribution and reproduction in any medium, provided the work is properly cited. 